\title{
IDENTIFIKASI METABOLIT SEKUNDER DAN AKTIVITAS ANTIOKSIDAN EKSTRAK BUNGA TAPAK DARA (CATHARANTHUS ROSEUS)
}

\author{
Indri Verrananda M*., Victoria Yulita F., Lizma Febrina, Laode Rijai \\ Laboratorium Penelitian dan Pengembangan FARMAKA TROPIS, Fakultas Farmasi \\ Universitas Mulawarman, Samarinda, Kalimantan Timur \\ *email : indrivmadhani@gmail.com
}

\begin{abstract}
ABSTRAK
Telah dilakukan penelitian mengenai identifikasi metabolit sekunder dan aktivitas antioksidan ekstrak bunga tapak dara (Catharanthus rosus) dengan metode DPPH (2,2difenil-1-pikrilhidrazil). Hasil uji fitokimia menunjukkan bahwa ekstrak metanol bunga tapak dara mengandung alkaloid, flavonoid, fenolik, tanin, dan terpenoid, sedangkan fraksi n-heksan mengandung tanin, fraksi etil asetat mengandung alkaloid, flavonoid, fenolik dan tanin, serta fraksi n-butanol mengandung alkaloid, flavonoid, fenolik, tanin dan terpenoid. Sementara, nilai $\mathrm{IC}_{50}$ yang diperoleh dari metode DPPH menunjukkan bahwa ekstrak bunga tapak dara memiliki potensi antioksidan dengan nilai $\mathrm{IC}_{50}$ sebesar $142,914 \mathrm{ppm}$, fraksi nheksan dengan nilai $\mathrm{IC}_{50}$ sebesar 503,037 ppm, fraksi etil asetat dengan nilai $\mathrm{IC}_{50}$ sebesar 50,069 ppm, dan fraksi n-butanol dengan nilai $\mathrm{IC}_{50}$ sebesar 170,122 ppm. Hasil penelitian ini menunjukkan bahwa ekstrak bunga tapak dara berpotensi sebagai antioksidan, hal ini ditandai dengan nilai $\mathrm{IC}_{50}$ yang diperoleh dan dengan adanya senyawa metabolit sekunder yang berkhasiat sebagai antioksidan.
\end{abstract}

Kata kunci : Tapak dara (Catharanthus roseus), Metabolit Sekunder, Antioksidan.

\begin{abstract}
We report the identification of secondary metabolites and antioxidant activity of the Catharanthus rosus flowers extract with DPPH (2,2-diphenyl-1-picrylhydrazyl). Results of phytochemical test showed that the methanol extract of Catharanthus rosus contains alkaloids, flavonoids, phenolics, tannins, and terpenoids, while the fraction of n-hexane contains tannins, ethyl acetate fraction contains alkaloids, flavonoids, phenolics and tannins, as well as n-butanol fraction contains alkaloids, flavonoids, phenolics, tannins and terpenoids. Meanwhile, antioxidant test showed that Catharanthus rosus flowers extract has potency with $I C_{50}$ value of 142.914 ppm, n-hexane fraction 503.037 ppm, ethyl acetate fraction $50.069 \mathrm{ppm}$, and $n$ - butanol fraction $170.122 \mathrm{ppm}$. The results of this study indicate that Catharanthus rosus flowers extract potential as an antioxidant which characterized by $I C_{50}$ values and its secondary metabolites that efficatious as an antioxidant.
\end{abstract}

Keywords : Vinca rosea (Catharanthus roseus), Secondary metabolites, Antioxidant.

\section{PENDAHULUAN}

Dalam kehidupan sehari-hari, kita tidak dapat terbebas dari senyawa radikal bebas. Asap rokok, makanan yang digoreng, dibakar, paparan sinar matahari berlebih, asap kendaraan bermotor, obat-obat tertentu, racun dan polusi udara merupakan beberapa sumber pembentuk senyawa radikal bebas. Radikal bebas merupakan molekul yang memiliki satu atau lebih elektron yang tidak berpasangan. Elektron-elektron yang tidak berpasangan ini 
menyebabkan radikal bebas menjadi senyawa yang sangat reaktif terhadap sel-sel tubuh dengan cara mengikat elektron molekul sel. Reaksi ini sering disebut sebagai reaksi oksidasi (Umayah, 2007).

Berbagai bukti ilmiah menunjukkan bahwa resiko penyakit kronis akibat senyawa radikal bebas dapat dikurangi dengan memanfaatkan peran senyawa antioksidan seperti vitamin C, E, A, karoten, asam-asam fenol, polifenol dan flavonoid (Prakash, 2001).

Antioksidan merupakan senyawa kimia yang dapat menyumbangkan elektron yang dikandungnya kepada radikal bebas. Secara alami, tubuh dapat menghasilkan senyawa antioksidan yaitu antioksidan enzimatik dan non enzimatik. Namun, senyawa antioksidan tersebut tidak mampu menghambat oksidan yang terbentuk akibat stress oksidatif (Silalahi, 2006). Hal tersebut menyebabkan diperlukannya antioksidan eksogen. Antioksidan eksogen dapat diperoleh secara sintetik maupun alami. Namun penggunaan antioksidan sintetik seperti asam benzoat, BHA (Butylated Hydroxy Anisol), BHT (Butylated Hydroxy Toluene) dan TBHQ (Tertier Butylated Hydroxy Quinone) dapat menimbulkan efek samping pada kesehatan tubuh, sehingga pemilihan antioksidan eksogen alami lebih dianjurkan karena keamanannya.

Tapak dara (Catharanthus roseus) adalah salah satu bahan alam yang telah banyak diteliti dan dilaporkan banyak memiliki khasiat dalam menyembuhkan berbagai macam penyakit, antara lain sebagai anti kanker (antineoplastik), peluruh kencing (diuretik), menurunkan tekanan darah (hipotensif), penenang (sedatif), penghenti perdarahan (hemostatis), serta menghilangkan panas dan racun. Pada bagian daun tapak darah terdapat komponen antikanker yaitu senyawa alkaloid seperti vinblastin (VLB), vinkristin (leurokristin $=\mathrm{VCR}$ ), leurosin $(\mathrm{VLR})$. Sedangkan pada akar tapak darah mengandung alkaloid, saponin, flavonoid dan tanin yang berkhasiat sebagai peluruh haid (Muhlisah, 2007).

Banyaknya penelitian terkait tanaman tapak dara, mendasari peneliti untuk melakukan penelitian terhadap bunga tapak dara yang belum banyak dilaporkan khasiatnya. Warna khas yang dimiliki bunga tapak dara merupakan ciri-ciri suatu tumbuhan yang memiliki aktivitas antioksidan, sehingga dilakukan penelitian untuk menguji aktivitas antioksidan dara tumbuhan ini. Pengujian aktivitas antioksidan dilakukan terhadap ekstrak metanol bunga tapak dara, fraksi n-heksan, fraksi etil asetat dan fraksi n-butanol bunga tapak dara. Pengujian aktivitas antioksidan dilakukan dengan menggunakan metode DPPH. Metode DPPH menggunakan 2,2-difenil-1-pikrilhidrazil sebagai sumber radikal bebas. Prinsipnya adalah reaksi penangkapan hidrogen oleh DPPH dari zat antioksidan. Pada metode ini, DPPH berperan sebagai radikal bebas yang direndam oleh antioksidan dari bahan uji, dimana DPPH akan bereaksi dengan antioksidan tersebut membentuk 1,1-difenil-2-pikrilhidrazil. Reaksi ini menyebabkan terjadinya perubahan warna yang dapat diukur dengan spektrofotometer sinar tampak pada $517 \mathrm{~nm}$ (Juniarti et al., 2009). Selain menguji aktivitas antioksidan, peneliti juga akan mengidentifikasi kandungan metabolit sekunder dari bunga tapak dara.

\section{METODE PENELITIAN}

\section{Bahan dan Alat}

Bahan pada penelitian ini adalah bunga tapak dara (Catharanthus roseus) yang diperoleh di kota Samarinda, DPPH, pelarut metanol, $n$-heksan, etil asetat, dan $n$-butanol. Alat yang digunakan pada penelitian ini adalah oven, rotary evaporator, timbangan analitik, tabung reaksi, vortex, dan Spektrofotometer UV-Vis. 


\section{Preparasi Sampel}

Dikeringkan bunga tapak dara $(2.250 \mathrm{~g})$ yang telah dipisahkan dari tangkai dan pengotor lainnya dengan oven pada suhu $40{ }^{\circ} \mathrm{C}$. Setelah diperoleh simplisia bunga tapak dara (185 g), kemudian simplisia disimpan di wadah yang kedap udara dan tidak lembab.

\section{Ekstraksi}

Simplisia (185 g) diekstraksi dengan menggunakan metode maserasi pada suhu ruang dengan pelarut metanol. Maserasi dilakukan 2-3 kali hingga pelarut menjadi bening. Hasil maserasi kemudian dipekatkan dengan rotary evaporator, kemudian pelarut diuapkan dengan water bath hingga diperoleh ekstrak kental, lalu ditimbang berat ekstrak yang diperoleh untuk kemudian dihitung rendemen ekstraknya.

\section{Fraksinasi}

Ekstrak kental (20 g) dipisahkan lebih lanjut dengan fraksinasi cair-cair. Ekstrak kental dilarutkan dalam $n$-heksan dan aquades $(100 \mathrm{~mL}: 100 \mathrm{~mL})$, kemudian dipartisi berulang dengan $n$-heksana $(800 \mathrm{~mL})$. Hasil yang diperoleh yaitu fasa $n$-heksan dan fasa air. Fasa air dipartisi cair-cair lebih lanjut dengan pelarut etil asetat, kemudian dipartisi berulang dengan etil asetat $(600 \mathrm{~mL})$. Hasil yang diperoleh yaitu fasa etil asetat dan fasa air. Fasa air dipartisi cair-cair lebih lanjut dengan pelarut $n$-butanol, kemudian dipartisi berulang dengan $n$ butanol (1,2 L). Hasil yang diperoleh yaitu $n$-butanol dan fasa air. Kemudian diuapkan masing-masing pelarut dengan menggunakan water bath, lalu ditimbang berat fraksi yang diperoleh untuk kemudian dihitung rendemen fraksi.

\section{Pengujian Metabolit Sekunder}

\section{Uji Alkaloid}

Ekstrak dan fraksi ( $2 \mathrm{~mL}$ ) diuapkan di atas cawan porselin. Residu yang dihasilkan kemudian dilarutkan dengan $5 \mathrm{~mL} \mathrm{HCl} 2 \mathrm{M}$. Larutan yang diperoleh dibagi ke dalam 3 tabung reaksi. Tabung pertama berfungsi sebagai blanko, ditambahkan dengan 3 tetes $\mathrm{HCl}$ 2 M. Tabung kedua ditambahkan 3 tetes pereaksi Dragendorff dan tabung ketiga ditambahkan 3 tetes pereaksi Mayer. Uji positif ditunjukkan dengan terbentuknya endapan berwarna jingga sedangkan pereaksi Mayer dengan terbentuknya endapan berwarna kuning.

\section{Uji Fenolik}

Ekstrak dan fraksi $(1 \mathrm{~mL})$ dimasukkan ke dalam tabung reaksi, kemudian ditambahkan pereaksi $\mathrm{FeCl}_{3} 1 \%$. Uji positif ditunjukkan dengan terbentuknya warna hitam.

\section{Uji Flavonoid}

Ekstrak dan fraksi ( $2 \mathrm{~mL}$ ) ditambahkan dengan air panas, kemudian dididihkan selama 5 menit lalu disaring. Filtrat sebanyak $5 \mathrm{~mL}$ ditambahkan $0,05 \mathrm{mg}$ serbuk $\mathrm{Mg}$ dan $1 \mathrm{~mL} \mathrm{HCl}$ pekat, kemudian dikocok. Uji positif ditunjukkan dengan terbentuknya warna merah, kuning atau jingga.

\section{Uji Saponin}

Ekstrak dan fraksi (2-3 mL) dimasukkan ke dalam tabung reaksi, kemudian ditambahkan dengan $10 \mathrm{~mL}$ air panas lalu didinginkan dan dikocok kuat selama 10 detik, lalu ditambahkan 1 tetes $\mathrm{HCl} 2 \mathrm{~N}$. Uji positif ditunjukkan dengan terbentuknya buih yang stabil setinggi $1-10 \mathrm{~cm}$ selama 10 menit. 


\section{Uji Steroid dan Terpenoid}

Ekstrak dan fraksi $(2 \mathrm{~mL})$ ditambahkan asam asetat glasial dan $\mathrm{H}_{2} \mathrm{SO} 4$ pekat, kemudian larutan dikocok perlahan. Uji positif steroid ditunjukkan dengan terbentuknya warna biru atau hijau, sedangkan triterpenoid memberikan warna merah atau ungu.

\section{Uji Tanin}

Ekstrak dan fraksi (1 mL) ditambahkan dengan beberapa tetes larutan $\mathrm{FeCl}_{3} 10 \%$. Uji positif ditunjukkan dengan terbentuknya warna hitam kehijauan.

\section{Pembuatan Larutan Uji}

Dilarutkan ekstrak dan masing-masing fraksi dengan pelarut metanol, kemudian dibuat dalam berbagai konsentrasi untuk selanjutnya dilakukan uji antioksidan.

\section{Pembuatan Larutan DPPH}

Ditimbang DPPH untuk dilarutkan dalam metanol tepat pada konsentrasi $40 \mathrm{ppm}$. Kemudian segera digunakan dan dijaga temperatur serta terlindung dari cahaya.

\section{Pembuatan Blanko}

Sebanyak $2 \mathrm{~mL}$ larutan DPPH ditambahkan dengan $2 \mathrm{~mL}$ metanol lalu dihomogenkan dengan menggunakan vortex. Kemudian digunakan untuk menentukan panjang gelombang maksimum DPPH yang digunakan untuk pengujian.

\section{Pengujian Aktivitas Antioksidan}

Sebanyak $2 \mathrm{~mL}$ sampel masing-masing dimasukkan ke dalam tabung reaksi, lalu ditambahkan ke dalamnya $2 \mathrm{~mL}$ larutan DPPH $40 \mathrm{ppm}$. Campuran tersebut kemudian dihomogenkan dengan menggunakan vortex. Selanjutnya, diinkubasi selama 30 menit dalam ruang gelap. Serapan diukur pada panjang gelombang maksimum pada spektrofotometer $\mathrm{UV}-\mathrm{Vis}$.

\section{HASIL PENELITIAN}

\section{Ekstraksi dan Fraksinasi}

Simplisia bunga tapak dara dimaserasi dengan pelarut metanol untuk mengekstraksi komponen kimia baik yang polar maupun nonpolar. Remaserasi dilakukan hingga pelarut menjadi bening, dimana pelarut yang telah bening tersebut menandakan bahwa diperkirakan senyawa metabolit sekunder yang terkandung pada simplisia telah tertarik seluruhnya oleh pelarut. Adapun ekstrak kental metanol yang didapatkan yaitu 96,7 g.

Fraksinasi dilakukan dengan metode cair-cair, yaitu pemisahan lebih lanjut dengan menggunakan pelarut bertingkat dengan tingkat kepolaran yang berbeda. Adapun dilakukan fraksinasi pada ekstrak bunga tapak dara yaitu untuk memisahkan senyawa-senyawa yang terkandung dalam ekstrak berdasarkan perbedaan kepolarannya. Berat fraksi yang diperoleh yaitu, pada fraksi $n$-heksan seberat $4,8 \mathrm{~g}$, fraksi etil asetat yaitu $1,1 \mathrm{~g}$, dan fraksi $n$-butanol yaitu 4,7 g. Adapun persentase nilai rendemen ekstrak dan fraksi dapat dilihat pada Tabel 1.

Tabel 1. Persentase Rendemen Ekstrak dan Fraksi Bunga Tapak Dara (Catharanthus roseus)

\begin{tabular}{ll}
\hline Sampel & \% Rendemen \\
\hline Ekstrak metanol & $52,270 \%$ \\
Fraksi $n$-Heksan & $24 \%$ \\
Fraksi etil asetat & $5,5 \%$ \\
Fraksi $n$-Butanol & $23,5 \%$ \\
\hline
\end{tabular}




\section{Uji Fitokimia}

Analisis fitokimia merupakan salah satu cara untuk mengetahui kandungan metabolit sekunder pada suatu tanaman secara kualitatif. Analisis fitokimia pada penelitian ini dilakukan terhadap tanaman bunga tapak dara yang sudah dimaserasi menggunakan pelarut metanol dan difraksinasi secara bertingkat dengan pelarut $n$-heksan, etil asetat dan $n$-butanol. Senyawa-senyawa yang diperiksa keberadaannya adalah alkaloid, fenolik, flavonoid, saponin, steroid dan terpenoid.

Hasil analisis fitokimia pada ekstrak dan fraksi bunga tapak dara (Catharanthus roseus) dapat dilihat pada Tabel 2.

Tabel 2. Uji Fitokimia Ekstrak dan Fraksi Bunga Tapak Dara (Catharanthus roseus)

\begin{tabular}{lllll}
\hline Uji & Ekstrak & Fraksi & Fraksi & Fraksi \\
Fitokimia & Metanol & $\boldsymbol{n}$-Heksan & Etil asetat & $\boldsymbol{n}$-Butanol \\
\hline Alkaloid & + & - & + & + \\
Fenolik & + & - & + & + \\
Flavonoid & + & - & + & + \\
Saponin & - & - & - & - \\
Steroid & - & - & - & - \\
Terpenoid & + & - & - & + \\
Tanin & + & + & + & + \\
\hline
\end{tabular}

\section{Pengujian Aktivitas Antioksidan}

Pengujian aktivitas antioksidan dilakukan pada ekstrak metanol, fraksi $n$-heksan, fraksi etil asetat dan fraksi $n$-butanol. Pengujian aktivitas antioksidan dilakukan dengan menggunakan metode DPPH, dimana metode ini merupakan metode pengukuran antioksidan yang sensitif, sederhana, cepat dan tidak membutuhkan banyak reagen (Ozcelik, 2003).

Aktivitas peredaman radikal bebas DPPH ekstrak bunga tapak dara dihasilkan oleh berbagai senyawa antioksidan yang terdapat di dalam bunga tapak dara. Semakin besar konsentrasi sampel, maka semakin banyak elektron yang didonorkan untuk meredam radikal DPPH, sehingga serapan yang diberikan pun semakin menurun. Keberadaan senyawa antioksidan dalam larutan uji dapat mengubah warna larutan DPPH yang berwarna ungu menjadi kuning (Dehpour, 2009).

Adapun nilai IC $_{50}$ dari masing-masing ekstrak dan fraksi dapat dilihat pada Tabel 3.

Tabel 3. Nilai IC $_{50}$ ekstrak dan Fraksi Bunga Tapak Dara (Catharanthus roseus)

\begin{tabular}{ll}
\hline Sampel & Nilai IC50 \\
\hline Ekstrak metanol & $142,914 \mathrm{ppm}$ \\
Fraksi $n$-Heksan & $503,037 \mathrm{ppm}$ \\
Fraksi etil asetat & $50,069 \mathrm{ppm}$ \\
Fraksi $n$-Butanol & $170,122 \mathrm{ppm}$ \\
\hline
\end{tabular}

Hasil uji aktivitas antioksidan menunjukkan bahwa semua sampel memiliki aktivitas antioksidan. Fraksi etil asetat memiliki aktivitas peredaman DPPH lebih besar daripada ekstrak metanol, fraksi $n$-heksan dan fraksi $n$-butanol. Hal ini mungkin dikarenakan pada fraksi etil asetat mengandung senyawa berkhasiat antioksidan yang lebih banyak dibandingkan dengan fraksi lain, sedangkan pada ekstrak metanol masih terdapat banyak 
golongan metabolit sekunder yang menutupi senyawa antioksidan sehingga diperoleh aktivitas antioksidan yang lebih kecil dibandingkan fraksi etil asetat. Untuk mengetahui senyawa aktif yang memberikan aktivitas antioksidan perlu dilakukan penelitian lanjutan berupa skrining dan isolasi senyawa aktif yang dipandu oleh uji aktivitas.

\section{KESIMPULAN}

Hasil analisis menunjukkan bahwa ekstak bunga tapak dara berpotensi sebagai antioksidan dengan nilai $\mathrm{IC}_{50}$ yang diperoleh dan adanya senyawa metabolit sekunder yang berkhasiat sebagai antioksidan.

\section{DAFTAR PUSTAKA}

Dehpour, A.A., Ebrahimzadeh, M.A., Fazel, N.S., and Mohammad, N.S., 2009, Antioxidant Activity of Methanol Extract of Ferula Assafoetida and Its Essential Oil Composition. Grasas Aceites. Vol. 60 No. 4.

Juniarti, Delvi, O. dan Yuhernita, 2009, Kandungan Senyawa Kimia, Uji Toksisitas (Brine Shrimp Lethality Test) dan Antioksidan (1,1-diphenyl-2-pikrilhydrazyl) dari Ekstrak Daun Saga (Abrus precatorius L.). Makara Sains. Vol. 13 No. 1.

Muhlisah, F., 2007, Tanaman Obat Keluarga. Penebar Swadaya. Jakarta.

Ozcelik, O., Lee, J.H., and Minn, D.B, 2003, Effect of Light, Oxygen and pH on The Absorbance of 2,2-dipheny 1-1-picrylhydrazyl. Journal of Food Science. Vol. 68.

Prakash, A., 2001, Antioxidant Activity. Medallion Laboratories Analitical Progres. Vol. 12 No. 2.

Silalahi, J., 2006, Makanan Fungsional. Kanisius. Yogyakarta.

Umayah, E., dan Amrun, M., 2007, Uji Aktivitas Antioksidan Ekstrak Buah Naga (Hylocereus undatus (Haw.) Britt. \& Rose). Jurnal Ilmu Dasar. Vol. 8 No. 1. 